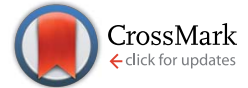

Cite this: RSC Adv., 2017, 7, 2503

Received 31st October 2016 Accepted 18th December 2016 DOI: $10.1039 / c 6 r a 26076 d$

www.rsc.org/advances

\section{Matrix isolation FTIR study of hydrogen-bonded complexes of methanol with heterocyclic organic compounds $\uparrow$}

\author{
Xiaotong Jiang, Shijie Liu, Narcisse T. Tsona, Shanshan Tang, Lei Ding, Hailiang Zhao \\ and Lin Du*
}

Acting as hydrogen bond acceptors, heterocyclic compounds could interact with a hydrogen bond donor, where either the heteroatom or the $\pi$ system is the bonding site. The hydrogen bonded complexes of heterocyclic compounds with methanol $(\mathrm{MeOH})$ were studied using matrix isolation FTIR spectroscopy and theoretical calculations based on density functional theory. Four heterocyclic compounds, furan (Fu), 2,5-dihydrofuran (DHF), pyrrole (Py) and thiophene (Th) were selected as representative examples for acceptors. For each of the $\mathrm{MeOH}-\mathrm{Fu}, \mathrm{MeOH}-\mathrm{DHF}$ and $\mathrm{MeOH}-\mathrm{Th}$ complexes, the $\mathrm{O}-\mathrm{H} \cdots \pi$ and $\mathrm{O}-\mathrm{H} \cdots \mathrm{Y}(\mathrm{Y}=\mathrm{O}, \mathrm{S})$ hydrogen bonded structures were obtained, while an $\mathrm{N}-\mathrm{H} \cdots \mathrm{O}$ instead of $\mathrm{O}-\mathrm{H} \cdots \mathrm{N}$ hydrogen bonded conformer was found in the $\mathrm{MeOH}-\mathrm{Py}$ complex. The measured $\mathrm{OH}$-stretching transitions of the complexes in the IR spectra were assigned to the $\mathrm{O}-\mathrm{H} \cdots \mathrm{O}$ bonded $\mathrm{MeOH}-\mathrm{Fu}$ (b) and $\mathrm{MeOH}-\mathrm{DHF}$ (b) conformers and the $\mathrm{N}-\mathrm{H} \cdots \mathrm{O}$ bonded $\mathrm{Py}-\mathrm{MeOH}$ (b) conformer, respectively. However, it was hard to assign the spectra to the exact $\mathrm{MeOH}-\mathrm{Th}$ conformer, because all the hydrogen bond characteristic features obtained for different $\mathrm{MeOH}-\mathrm{Th}$ conformers are too close. DHF forms a stronger $\mathrm{O}-\mathrm{H} \cdots \mathrm{O}$ hydrogen bond than furan, and the $\mathrm{O}-\mathrm{H} \cdots \mathrm{O}$ hydrogen bonded $\mathrm{MeOH}-\mathrm{Fu}$ complex is more stable than the $\mathrm{O}-\mathrm{H} \cdots \mathrm{S}$ bonded $\mathrm{MeOH}-\mathrm{Th}$ complex. Atoms in molecules analysis was also performed to understand the nature of interaction in the $\mathrm{MeOH}$ complexes. This analysis allowed us to characterize the new bond critical point generated in the complexes. The present results help to evaluate the atmospheric behavior of some heterocyclic compounds, and indicate their importance in the prenucleation mechanism at the molecular level.

\section{Introduction}

The hydrogen bond plays an important role in atmospheric chemistry, especially in the field of aerosol formation and growth. ${ }^{\mathbf{1 - 4}}$ Many experimental and theoretical investigations have been performed to understand intermolecular hydrogen bonds, with a focus on structural, spectroscopic and energetic issues. ${ }^{5-8}$ Hydrogen bonded complexes usually have small equilibrium constants, which make them difficult to study under atmospheric conditions. Therefore, these complexes are often studied experimentally under some form of cooling to favor complex formation. ${ }^{9-15}$

Owing to the low temperature, matrix isolation infrared spectroscopy study is considered as a useful analysis technique for observing and characterizing hydrogen bonded interactions in complexes. Matrix isolation Fourier transform infrared spectroscopy (FTIR) coupled with ab initio calculations has been

Environment Research Institute, Shandong University, Shanda South Road 27, 250100 Shandong, China. E-mail: lindu@sdu.edu.cn

$\uparrow$ Electronic supplementary information (ESI) available. See DOI: 10.1039/c6ra26076d employed for the isolation and characterization of a wide range of molecular complexes and reactive Criegee intermediates. The study of intermolecular interactions between sulfuric acid and several molecules of atmospheric interest have been carried out using matrix isolation spectroscopic methods. ${ }^{10,16-18}$ For instance, the interactions in the $\mathrm{H}_{2} \mathrm{SO}_{4} / \mathrm{CH}_{3} \mathrm{OH} / \mathrm{H}_{2} \mathrm{O}$ system have been studied by matrix isolation FTIR spectroscopy in conjunction with density functional theory calculations. Several new bands observed from the FTIR spectra indicate the existence of the $1: 1: 1 \mathrm{H}_{2} \mathrm{SO}_{4} / \mathrm{CH}_{3} \mathrm{OH} / \mathrm{H}_{2} \mathrm{O}$ cycle complex. ${ }^{18}$ The effect of hydrogen bond on the anharmonicity and intensity of $\mathrm{OH}$ oscillators in $\mathrm{MeOH}$ trapped in neon matrix has been investigated using near-infrared (NIR) and middle infrared (MIR) spectroscopy. The anharmonicity parameters were determined from the positions and intensities of the dimer bands of $\mathrm{MeOH} .{ }^{19}$ For the purpose of discriminating between $\mathrm{O}-\mathrm{H} \cdots \mathrm{N}$ and $\mathrm{O}-\mathrm{H} \cdots \mathrm{O}=\mathrm{C}$ complexes, a deep research of matrix isolation FTIR spectra and the hydrogen bonded complexes with $\mathrm{MeOH}$ in argon has been taken. ${ }^{20}$ It was concluded that hydrogen bonds between weak acids such as $\mathrm{MeOH}$ tends to be formed at the carbonyl group. Gas phase reaction of phosphorus trichloride $\left(\mathrm{PCl}_{3}\right)$ and $\mathrm{MeOH}$ was carried out at different 
ratios of $\mathrm{PCl}_{3} / \mathrm{MeOH}$ and the products were identified using matrix isolation infrared spectroscopy. ${ }^{21}$ Infrared vibrational spectra of matrix isolated $\mathrm{PCl}_{3}, \mathrm{MeOH}$ and their complexes were analyzed and assigned by comparing the observed and calculated frequencies and intensities. The experimental evidence for the noncovalent $\mathrm{P} \cdots \mathrm{O}$ interaction in $\mathrm{PCl}_{3}-\mathrm{MeOH}$ adducts was provided.

$\mathrm{MeOH}$ is one of the most abundant group of oxygenated volatile organic compounds, ${ }^{22,23}$ and is one of the simplest stable organic compounds capable of forming intermolecular hydrogen bonded complexes. A number of studies have been carried out to investigate the red shifts of $\mathrm{OH}$-stretching vibrational frequency in $\mathrm{MeOH}$ clusters since they provide sensitive probes for the hydrogen bond interaction. ${ }^{7,24-27}$ The $\mathrm{OH}-$ stretching transition for the interaction between two constituent $\mathrm{MeOH}$ molecules has a $111 \mathrm{~cm}^{-1}$ red shift in the jet-cooled gas phase, which has been augmented with information on its diagonal anharmonicity. ${ }^{27}$ The study of hydrogen bonded $\mathrm{MeOH}$ complexes has been performed by vapor phase infrared spectroscopy. In order to obtain experimental evidence for NIR transitions in complexes, the spectroscopic studies of hydrogen bond in the vapor phase involving $\mathrm{MeOH}$ and trimethylamine (TMA) have been performed. Upon complexation to TMA, the $\mathrm{OH}$-stretching frequency of $\mathrm{MeOH}$ was red shifted by $186 \mathrm{~cm}^{-1}$ relative to the $\mathrm{MeOH}$ monomer. The first $\mathrm{OH}$-stretching overtone transition of the complex is tentatively assigned at 6450 $\mathrm{cm}^{-1} \cdot{ }^{26}$ Gas phase vibrational spectra of the bimolecular complex formed between $\mathrm{MeOH}$ and dimethylamine (DMA)/ TMA have also been measured to determine the enthalpy of complexation for the $\mathrm{MeOH}-\mathrm{DMA}$ and $\mathrm{MeOH}-\mathrm{TMA}$ complexes in the temperature range $298-358 \mathrm{~K}$. The spectroscopic infrared results show the enthalpy of formation to be $-35.8 \pm 3.9$ and $-38.2 \pm 3.3 \mathrm{~kJ} \mathrm{~mol}^{-1}$ for MeOH-DMA and MeOH-TMA, respectively. ${ }^{24}$ Furthermore, the detection of the $\mathrm{O}-\mathrm{H} \cdots \pi$ interactions between $\mathrm{MeOH}$ and alkenes has also caused much attention in recent years. An FTIR spectroscopic study of small isolated clusters of $\mathrm{MeOH}$ and ethene has been performed with experimental red shifts of $45 \mathrm{~cm}^{-1}$ from the $\mathrm{MeOH}$ monomer fundamental position at $3686 \mathrm{~cm}^{-1}$, which confirms the formation of weak intermolecular hydrogen bond to a $\pi$ cloud. $^{7}$ A systematic study of the methylation of anisole to change the $\pi$ cloud attractivity relative to the oxygen side for the docking of $\mathrm{MeOH}$ has been undertaken by supersonic jet-FTIR. The spectroscopic method of determining the docking preference of $\mathrm{MeOH}$ to anisole is found to reveal that the subtle balance between these two structures can be varied by one order of magnitude through single to triple methylation of the aromatic ring and introduction of a single tert-butyl substituent. ${ }^{25}$

Heterocyclic organic compounds containing oxygen, nitrogen, or sulfur, are an important group of atmospheric pollutants and they are the basic units of brown carbon, which is well known to be an important component in the atmosphere where it affects climate forcing and carbon cycling. ${ }^{28-30}$ Four heterocyclic compounds were selected as the representative examples for acceptors in this study: furan (Fu), 2,5-dihydrofuran (DHF), pyrrole (Py) and thiophene (Th). Among them, furan and its derivatives, such as, 2,5-dihydrofuran, are both primary and secondary pollutants in the atmosphere, and their emission contributes to the formation of ultrafine particles and ground-level ozone. ${ }^{31,32}$ Besides, furans can react with the atmospheric radicals and affect the oxidative budget of the lower troposphere. ${ }^{33}$ The atmospheric source of furan includes emissions from agricultural processes, atmospheric oxidation reactions of 1,3-butadiene and 1,3-pentadiene, tropical forest burning, food processing and direct emissions from plant material. $^{\mathbf{2 8 , 3 4 , 3 5}}$ Pyrrole was detected in biomass and biofuel burning, and it was identified as a potential light-absorption brown carbon. Atmospheric thiophene mainly comes from fossil fuel combustion. ${ }^{36}$ In order to evaluate the atmospheric behavior of these heterocyclic compounds, it is important to study their interaction with other atmospheric molecules, such as $\mathrm{MeOH}$.

The formation of new particles in the ambient atmosphere is a complex phenomenum, but the detailed molecular level processes and the exact participating molecules still remain largely unknown. $\mathrm{MeOH}$ is believed to be a common hydrogen bond donor to drive gas to particle conversion, ${ }^{37,38}$ and heterocyclic organic compounds are quite possible to be candidate species to stabilize $\mathrm{MeOH}$ clusters via hydrogen bond. In this work, the hydrogen bond between $\mathrm{MeOH}$ and four heterocyclic compounds including furan, DHF, pyrrole and thiophene were investigated using matrix isolation FTIR spectroscopy. Quantum chemical calculations of the $\mathrm{MeOH}-\mathrm{Fu}, \mathrm{MeOH}-\mathrm{DHF}$, $\mathrm{MeOH}-\mathrm{Th}$, and $\mathrm{MeOH}-\mathrm{Py}$ complexes were performed to help determine the most stable conformers and then interpret the spectra.

\section{Experimental and computational methods}

\subsection{Experimental details}

All the experiments were performed with a closed-cycle helium compressor cooled cryostat (PT-SHI-4-5, Janis Research Company, USA) to achieve low temperature. The cryostat was housed in a vacuum chamber. A pressure gauge (WRG-NW25, Edward, UK) was used to monitor the pressure inside the cryostat chamber. The base pressure of $10^{-5}$ mbar was generally recorded at the beginning of an experiment. The gas phase mixtures were co-deposited onto a diamond substrate at $14 \mathrm{~K}$. Temperatures at the cold surface were measured with a silicon diode sensor (DT-670, Lakeshore, USA), and the temperature was regulated by a temperature controller (model 22C, Cryocon, USA). The substrate was put in the sample beam of a FTIR spectrometer to allow spectral measurement. Argon (99.999\%, Deyang special gas company) was used as the matrix gas. $\mathrm{MeOH}$ (99.9\%, Aladdin), furan (99\%, Aladdin), DHF (97\%, Aladdin), pyrrole (99.7\%, Aladdin), and thiophene (99\%, Aladdin) were used without further purification. The argon/sample ratios ranged from $1 / 700$ to $5 / 700$.

The infrared spectra of the deposited samples were recorded at $0.5 \mathrm{~cm}^{-1}$ resolution with a Vertex $80 \mathrm{v}$ FTIR spectrometer (Bruker) fitted with a $\mathrm{KBr}$ beam splitter and liquid nitrogen cooled MCT (Mercury-Cadmium-Telluride) detector. The 
precursors were then separately deposited onto the diamond substrate at $14 \mathrm{~K}$. The deposition was annealed to $25 \mathrm{~K}, 30 \mathrm{~K}, 35$ $\mathrm{K}$ and maintained at each temperature for $30 \mathrm{~min}$, and then recooled to $14 \mathrm{~K}$. Spectra were recorded after each warming cycle to monitor any changes caused by these processes.

\subsection{Computational details}

Geometries optimizations and vibrational frequency calculations on the monomers $\mathrm{MeOH}, \mathrm{DHF}$, furan, pyrrole and thiophene) and the complexes (MeOH-Fu, MeOH-DHF, MeOH-Py, and $\mathrm{MeOH}-\mathrm{Th}$ ) were performed with Gaussian 09 computational program package using the "opt = very tight," and "int = ultrafine" options. ${ }^{39}$ Density functional theory (DFT) methods provide an adequate compromise between the desired chemical accuracy and the computational cost. The DFT-based functionals, such as the Becke-3 Lee-Yang-Parr (B3LYP), have been shown to provide reliable trends of bonding energies even though the small energy differences can be overshadowed by the DFT quadrature errors. ${ }^{40}$ Furthermore, DFT methods based on the B3LYP functional have also been indicated to produce quite accurate results for heterocyclic compounds. ${ }^{41}$ Besides the geometries optimizations, the harmonic vibrational frequency calculations were also performed with DFT methods with the absence of imaginary frequencies for all the structures of the relevant monomer and complexes, which ensured that the optimized structures were minima on the potential energy surface. The quantum chemical calculations enabled us to characterize the nature of the stationary points and also to assign the observed wavenumbers in our matrix isolation experiments. ${ }^{17}$ For comparison, M06-2X, $\omega$ B97X-D, and B3LYPD3 functionals were also used, and the data calculated with these functionals are shown in ESI. $\dagger$ We used the aug-cc-pVTZ basis set for compounds containing the $\mathrm{H}$ and $\mathrm{O}$ atoms, and the aug-cc-pV(T+d)Z basis sets for compounds containing the $\mathrm{S}$ atom. The extra tight $d$ functions in the aug-cc-pV(T+d)Z basis set has previously been shown to improve results for the third period atoms such as S. ${ }^{42,43}$ Thermal contributions to the energies were calculated under the harmonic oscillator-rigid rotor approximation. ${ }^{44}$ Corrected by the zero point vibrational energy (ZPVE) corrections, the energies changes were obtained through subtracting the energies of the two isolated reactants from the energy of the formed complexes:

$$
\Delta E=E_{\text {complex }}-\sum E_{\text {reactants }}
$$

The theory of atoms in molecules (AIM) is a topological method based on the electron density, $\rho(r)$, and is applied to investigate interactions between the two monomers forming the hydrogen bonded complexes. The AIM analysis was performed using the wave functions computed at the B3LYP/aug-cc-pVTZ level of theory. The positive sign of the Laplacian charge density at BCP $\nabla^{2} \rho(\mathrm{BCP})$ corresponds to closed shell interactions that are responsible for bonding, where electronic charge is concentrated around each nucleus. The bond critical points (BCPs) were evaluated from the B3LYP/aug-cc-pVTZ level using AIM 2000 program package (version 2). ${ }^{45}$ Generally, weak van der Waals type interactions are characterized by small values of the electron density and the Laplacian charge density. ${ }^{\mathbf{4 6}}$ In hydrogen bonded complexes, the electron density and the Laplacian charge density are in the range of 0.002-0.034 and 0.016-0.130 a.u. ${ }^{47}$ The charge transfer of the complexes were calculated by integrating the electron density of the $\mathrm{MeOH}$ within the complex.

\section{Results and discussion}

\subsection{Optimized geometries}

Optimized structures of the two most stable $\mathrm{MeOH}$ complex conformers (a, and b) with the B3LYP functional are shown in Fig. 1. $\mathrm{MeOH}$ forms hydrogen bonds with heterocyclic organic compounds in two ways, $\mathrm{O}-\mathrm{H} \cdots \pi$ and $\mathrm{O}-\mathrm{H} \cdots \mathrm{Y}(\mathrm{Y}=\mathrm{O}, \mathrm{S})$. In the $\mathrm{O}-\mathrm{H} \cdots \pi$ bonded structures, $\mathrm{MeOH}$ docks onto one side instead of the center of the heterocyclic organic compound ring. Previous studies have shown that a competition between $\mathrm{O}-\mathrm{H} \cdots \mathrm{O}$ and $\mathrm{O}-\mathrm{H} \cdots \pi$ binding sites exists when $\mathrm{MeOH}$ docks onto 2,3-benzofuran. ${ }^{48}$ Similarly, the heterocyclic organic compounds investigated in this study can offer two hydrogen bond acceptor sites to an incoming hydrogen bond donor: its heteroatom and its delocalized $\pi$ electron system. This bonding pattern has been found for the $\mathrm{MeOH}$-benzene and waterbenzene complexes. ${ }^{37}$ The docking motifs of $\mathrm{MeOH}$ and anisole have been studied by applying a cold supersonic jet expansion of the two monomers in helium. ${ }^{49}$ The results of this study showed that $\mathrm{MeOH}$ prefers the oxygen of anisole over the $\pi$ system. The $\mathrm{MeOH}$ forms a hydrogen bond with the oxygen of anisole, whereas docking onto the $\pi$ system is at least $1 \mathrm{~kJ} \mathrm{~mol}^{-1}$ less attractive and therefore hardly observable in the jet spectra. A competition of the $\mathrm{O}-\mathrm{H} \cdots \mathrm{O}$ versus $\mathrm{O}-\mathrm{H} \cdots \pi$ hydrogen bonds in 2,3-benzofuran clusters with water and $\mathrm{MeOH}$ molecules suggests that these two comparable conformers are almost equally stable. ${ }^{50}$ Two isomers having different types of hydrogen bonds are distinguished by applying fluorescence-detected infrared spectroscopy and dispersed fluorescence spectroscopy.

The geometric parameters including the $\mathrm{OH}$ bond lengths and the changes upon complexation, the intermolecular hydrogen bond distance and the hydrogen bond angle calculated using the B3LYP functional are provided in Table 1. The O-H $\cdots$ O hydrogen bond lengths lie between 1.8877 and 2.0749 $\AA$ with bond angle varying from $167.1^{\circ}$ to $173.4^{\circ}$. The intermolecular hydrogen bond distance in $\mathrm{MeOH}-\mathrm{Fu}$ (b) complex is about $0.2 \AA$ longer than that in the MeOH-DHF (b) complex, which indicates that $\mathrm{MeOH}-\mathrm{DHF}$ (b) complex forms a stronger $\mathrm{O}-\mathrm{H} \cdots \mathrm{O}$ hydrogen bond. The intermolecular hydrogen bond distance of the $\mathrm{O}-\mathrm{H} \cdots \mathrm{S}$ bonded $\mathrm{MeOH}-\mathrm{Th}$ (b) complex (2.7166 A) is $0.6 \AA$ A longer than that of the $\mathrm{MeOH}-\mathrm{Fu}$ (b) complex. The hydrogen bond distance in the $\mathrm{MeOH}$-dimethyl ether (DME) and $\mathrm{MeOH}$-dimethyl sulfide (DMS) complexes were reported to be $1.9085 \AA$ and $2.4207 \AA$ respectively, ${ }^{51}$ at the B3LYP/aug-ccpVTZ level. Both are smaller than the $\mathrm{O}-\mathrm{H} \cdots \mathrm{O}$ bonded $\mathrm{MeOH}-\mathrm{Fu}$ (b) and $\mathrm{O}-\mathrm{H} \cdots \mathrm{S}$ bonded $\mathrm{MeOH}-\mathrm{Th}$ (b) complex. This suggests that linear compounds, like DME and DMS, can form stronger hydrogen bond than the aromatic heterocyclic compounds, such as furan and thiophene. 

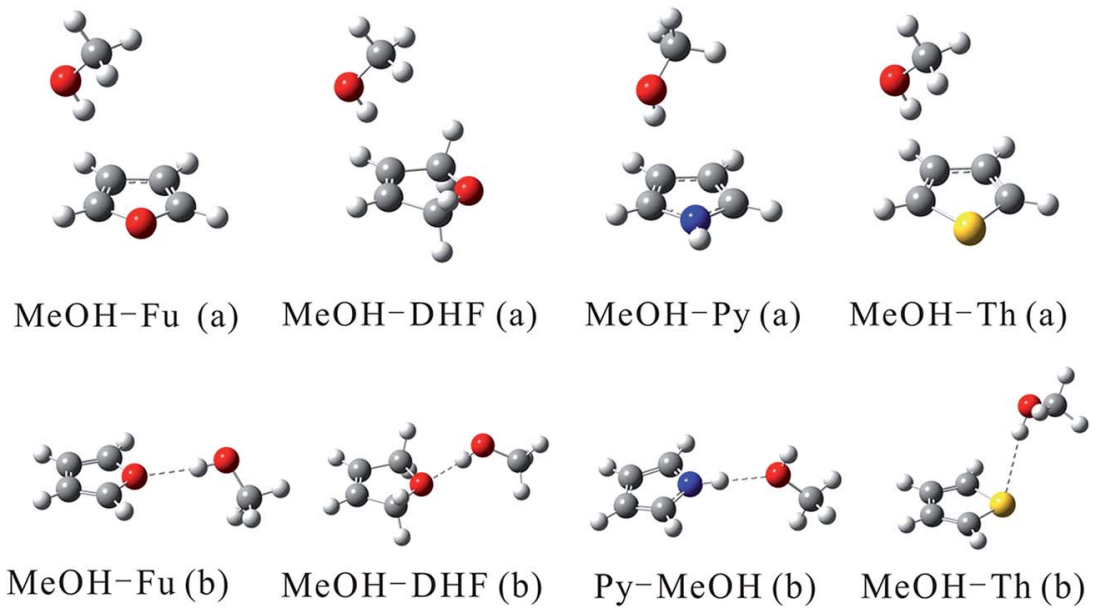

Fig. 1 Structures of the MeOH complexes optimized at the B3LYP/aug-cc-pVTZ and B3LYP/aug-cc-pV(T+d)Z levels of theory for complexes containing $\mathrm{O}$ and $\mathrm{N}$ atoms and those containing $\mathrm{S}$ atom, respectively.

In the $\mathrm{O}-\mathrm{H} \cdots \pi$ bonded conformers, the $\mathrm{OH}$ bond length ranges from $0.9634 \AA$ to $0.9752 \AA$. The change of $\mathrm{OH}$ bond lengths is more important in the $\mathrm{O}-\mathrm{H} \cdots \mathrm{O}$ bonded conformers. The $\mathrm{OH}$ bond is lengthened by $0.0029 \AA$ in the $\mathrm{MeOH}-\mathrm{DHF}(\mathrm{a})$, and $0.0095 \AA$ in the $\mathrm{MeOH}-\mathrm{DHF}$ (b) conformers, respectively. In the $\mathrm{MeOH}-\mathrm{Th}$ complexes, the changes of the $\mathrm{OH}$ bond length in the $\mathrm{O}-\mathrm{H} \cdots \mathrm{S}$ and $\mathrm{O}-\mathrm{H} \cdots \pi$ bonded conformers are very similar. The $\mathrm{OH}$ bond lengths and the changes in the $\mathrm{OH}$ bond length upon complexation are very similar for the $\mathrm{O}-\mathrm{H} \cdots \mathrm{O} / \mathrm{S}$ bonded $\mathrm{MeOH}-\mathrm{Fu}(\mathrm{b})$ and $\mathrm{MeOH}-\mathrm{Th}(\mathrm{b})$ conformers, which suggests that the ability of furan to weaken the $\mathrm{OH}$ bond via hydrogen bond is equivalent to that of thiophene. This result is consistent with comparison between the $\mathrm{MeOH}-\mathrm{DME}$ and $\mathrm{MeOH}-\mathrm{DMS}$ complexes. $^{51}$ Moreover, for $\mathrm{O}-\mathrm{H} \cdots \mathrm{O}$ hydrogen bonded complexes, the $\mathrm{OH}$ bond length elongation upon complexation of MeOH-DME (0.0086 $\AA$ ) is more important than that of $\mathrm{MeOH}-\mathrm{Fu}(\mathrm{b})(0.0030 \AA)$. A similar trend is also found in the $\mathrm{O}-\mathrm{H} \cdots \mathrm{S}$ bonded $\mathrm{MeOH}-\mathrm{DMS}(0.0091 \AA)$ and $\mathrm{MeOH}-\mathrm{Th}(\mathrm{b})$

Table 1 Selected optimized geometric parameters in the $\mathrm{MeOH}-\mathrm{Fu}$, $\mathrm{MeOH}-\mathrm{DHF}, \mathrm{MeOH}-\mathrm{Py}$ and $\mathrm{MeOH}-\mathrm{Th}$ complexes, calculated with the B3LYP functional (angles in degrees and bond lengths in $\AA$ )

\begin{tabular}{llllll}
\hline Conformer $^{a}$ & Bond type & $R(\mathrm{OH})^{b}$ & $\Delta r(\mathrm{OH})^{c}$ & $R(\mathrm{HB})^{d}$ & $\theta(\mathrm{HB})^{e}$ \\
\hline MeOH-Fu (a) & $\mathrm{O}-\mathrm{H} \cdots \pi$ & 0.9636 & 0.0028 & & \\
MeOH-Fu (b) & $\mathrm{O}-\mathrm{H} \cdots \mathrm{O}$ & 0.9638 & 0.0030 & 2.0749 & 167.1 \\
MeOH-DHF (a) & $\mathrm{O}-\mathrm{H} \cdots \pi$ & 0.9636 & 0.0029 & & \\
MeOH-DHF (b) & $\mathrm{O}-\mathrm{H} \cdots \mathrm{O}$ & 0.9702 & 0.0095 & 1.8877 & 173.4 \\
MeOH-Py (a) & $\mathrm{O}-\mathrm{H} \cdots \pi$ & 0.9652 & 0.0045 & & \\
Py-MeOH (b) & $\mathrm{N}-\mathrm{H} \cdots \mathrm{O}$ & 1.0109 & 0.0077 & 1.9844 & 178.7 \\
MeOH-Th (a) & $\mathrm{O}-\mathrm{H} \cdots \pi$ & 0.9634 & 0.0026 & & \\
MeOH-Th (b) & $\mathrm{O}-\mathrm{H} \cdots \mathrm{S}$ & 0.9633 & 0.0025 & 2.7166 & 168.2
\end{tabular}

${ }^{a}$ The $\mathrm{MeOH}-\mathrm{Th}$ complexes are calculated with the aug-cc-pV(T+d)Z basis set, and all other complexes with the aug-cc-pVTZ basis set, respectively. ${ }^{b} \mathrm{OH}$ bond length in the complex. ${ }^{c}$ Change in the $\mathrm{OH} /$ $\mathrm{NH}$ bond length upon complexation. ${ }^{d}$ The intermolecular hydrogen bond distance. ${ }^{e}$ The intermolecular hydrogen bond angle. ${ }^{f}$ In the Py$\mathrm{MeOH}(\mathrm{b})$ complex, $\mathrm{MeOH}$ acts as hydrogen bond acceptor. $R(\mathrm{NH})$ for pyrrole. $R\left(\mathrm{NH}_{\mathrm{b}} \cdots \mathrm{O}\right)$ and $\theta\left(\mathrm{NH}_{\mathrm{b}} \cdots \mathrm{O}\right)$ for the $\mathrm{Py}-\mathrm{MeOH}$ complexes.
$(0.0025 \AA)$ complexes. Among all the $\mathrm{O}-\mathrm{H} \cdots \mathrm{Y}$ bonded $\mathrm{MeOH}$ complexes, MeOH-DHF (b) shows the most important bond length change $\Delta r_{(\mathrm{OH})}$ and the smallest hydrogen bond length $r_{(\mathrm{HB})}$. DHF forms the strongest hydrogen bond in the heterocyclic organic compounds. Generally, the hydrogen bond angles are expected to be close to $180^{\circ}$ in an ideal hydrogen bonded complex. ${ }^{24,52}$ As seen in Table 1, the $\mathrm{O}-\mathrm{H} \cdots \mathrm{O} / \mathrm{S}$ hydrogen bond angles in $\mathrm{MeOH}-\mathrm{Fu}$ and $\mathrm{MeOH}-\mathrm{Th}$ deviate by $12^{\circ}$ from the ideal linear orientation. For the $\mathrm{O}-\mathrm{H} \cdots \mathrm{O}$ hydrogen bonded $\mathrm{MeOH}-$ DHF complexes, the angles only deviate by $6^{\circ}$. Generally, in similar hydrogen bonded $\mathrm{MeOH}$ complexes, smaller deviation of hydrogen bond angle represents more stable structure. As a result, $\mathrm{MeOH}-\mathrm{DHF}$ (b) is the most stable complex of all the $\mathrm{O}-\mathrm{H} \cdots \mathrm{Y}(\mathrm{Y}=\mathrm{O}, \mathrm{S})$ bonded complexes.

\subsection{Topological analysis}

AIM analysis was applied to describe the bonding in the $\mathrm{MeOH}$ complexes based on the topology of the electron density. ${ }^{53}$ Fig. 2 shows the AIM plots for the $\mathrm{MeOH}$ complexes with bond critical points (BCPs) and ring critical points (RCPs). The topological parameters, including electron density, Laplacian charge density, and change in atomic charge at the $\mathrm{H}$ atom $\Delta q(\mathrm{H})$ are listed in Table 4. Two quantitative criteria have been suggested to characterize the strength of a hydrogen bond. The electron density is in the range of $0.002-0.0340$ a.u. and the Laplacian charge density is in range of $0.016-0.130$ a.u.$^{47}$ The AIM analysis of these complexes shows only one $\mathrm{BCP}$ between the $\mathrm{MeOH}$ and each of the heterocyclic compounds. It is worth mentioning that, as shown in Table 2, the values of the electron density (0.0093-0.0295 a.u.) and the Laplacian charge density (0.02510.0865 a.u.) of the $\mathrm{MeOH}$ complexes were well within the range specified for the existence of the hydrogen bond. The positive and small values of the Laplacian charge density of the BCP's indicate the closed shell nature of the interactions similar to those found in hydrogen bonds and ionic interactions.

The charge density $\rho(\mathrm{BCP})$ at the BCP for the $\mathrm{O}-\mathrm{H} \cdots \pi$ interaction is about half of that for the $\mathrm{O}-\mathrm{H} \cdots \mathrm{O}$ interaction. The 

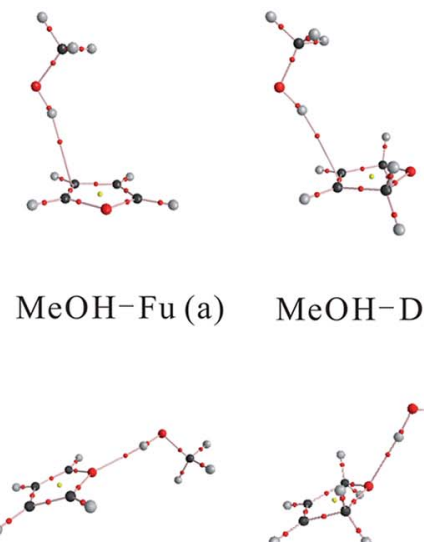

$\mathrm{MeOH}^{-} \mathrm{DHF}(\mathrm{a})$

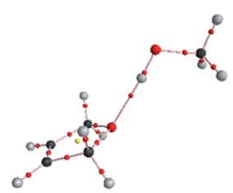

$\mathrm{MeOH}-\mathrm{Fu}(\mathrm{b})$
$\mathrm{MeOH}-\mathrm{DHF}(\mathrm{b})$

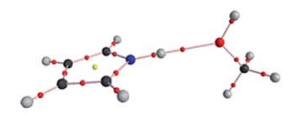

$\mathrm{Py}-\mathrm{MeOH}(\mathrm{b})$

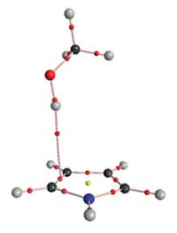

$\mathrm{MeOH}-\mathrm{Py}(\mathrm{a})$

$\mathrm{MeOH}^{-} \mathrm{Th}(\mathrm{a})$

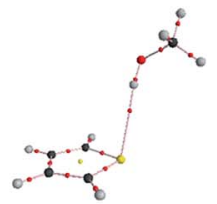

$\mathrm{MeOH}-\mathrm{Th}$

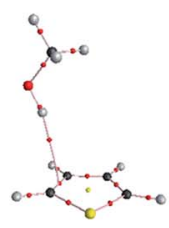

(b)

Fig. 2 AlM plots of the MeOH complexes with bond critical points (BCPs), ring critical points (RCPs) and electron density paths.

Laplacian charge density at BCP is also smaller for the $\mathrm{O}-\mathrm{H} \cdots \pi$ interaction than for the $\mathrm{O}-\mathrm{H} \cdots \mathrm{O}$ interaction. In addition, the loss of electronic charge on the hydrogen atom for $\mathrm{O}-\mathrm{H} \cdots \mathrm{O}$ hydrogen bond is more important than in the $\mathrm{O}-\mathrm{H} \cdots \pi$ hydrogen bond, confirming that the $\mathrm{O}-\mathrm{H} \cdots \mathrm{O}$ hydrogen bonded complex is more stable than the $\mathrm{O}-\mathrm{H} \cdots \pi$ bonded one. The charge density and Laplacian charge density of the $\mathrm{O}-\mathrm{H} \cdots \pi$ bonded $\mathrm{MeOH}-\mathrm{Th}$ (a) is almost similar to the $\mathrm{O}-\mathrm{H} \cdots \mathrm{S}$ bonded $\mathrm{MeOH}-\mathrm{Th}(\mathrm{b})$, indicating that these two $\mathrm{MeOH}-\mathrm{Th}$ isomers are almost equally stable.

\subsection{Interaction energies}

The calculated binding energy (BE), enthalpy of formation $\left(\Delta H^{\theta}\right)$ and Gibbs free energy of formation $\left(\Delta G^{\theta}\right)$ of the $\mathrm{MeOH}$ complexes are summarized in Table 3. As seen from Table 3, the ZPVE can be as large as $5.1 \mathrm{~kJ} \mathrm{~mol}^{-1}$. The BEs of $\mathrm{O}-\mathrm{H} \cdots \pi$ hydrogen bonded complexes range between -3.7 and $-8.1 \mathrm{~kJ}$ $\mathrm{mol}^{-1}$. Compared to the $\mathrm{O}-\mathrm{H} \cdots \mathrm{O}$ bonded conformers, the binding strengths in the $\mathrm{O}-\mathrm{H} \cdots \pi$ bonded conformers for $\mathrm{MeOH}-\mathrm{Fu}$ and $\mathrm{MeOH}-\mathrm{DHF}$ are weaker by $2.6 \mathrm{~kJ} \mathrm{~mol}^{-1}$ and 12.1 $\mathrm{kJ} \mathrm{mol}^{-1}$, respectively. The BEs clearly indicate that the $\mathrm{O}-\mathrm{H} \cdots \mathrm{O}$

Table 2 AIM parameters for the $\mathrm{MeOH}$ complexes optimized the B3LYP/aug-cc-pVTZ and B3LYP/aug-cc-pV(T+d)Z levels for complexes containing $\mathrm{O}$ and $\mathrm{N}$ atoms and those containing $\mathrm{S}$ atom, respectively ${ }^{a}$

\begin{tabular}{lllll}
\hline Conformer & Bond type & $\Delta q(\mathrm{H})$ & $\rho(\mathrm{BCP})$ & $\nabla^{2} \rho(\mathrm{BCP})$ \\
\hline MeOH-Fu (a) & $\mathrm{O}-\mathrm{H} \cdots \pi$ & 0.0045 & 0.0098 & 0.0271 \\
MeOH-Fu (b) & $\mathrm{O}-\mathrm{H} \cdots \mathrm{O}$ & 0.0298 & 0.0179 & 0.0651 \\
MeOH-DHF (a) & $\mathrm{O}-\mathrm{H} \cdots \pi$ & 0.0044 & 0.0104 & 0.0281 \\
MeOH-DHF (b) & $\mathrm{O}-\mathrm{H} \cdots \mathrm{O}$ & 0.0510 & 0.0295 & 0.0865 \\
MeOH-Py (a) & $\mathrm{O}-\mathrm{H} \cdots \pi$ & 0.0111 & 0.0116 & 0.0314 \\
Py-MeOH (b) & $\mathrm{N}-\mathrm{H} \cdots \mathrm{O}$ & 0.0504 & 0.0225 & 0.0791 \\
MeOH-Th (a) & $\mathrm{O}-\mathrm{H} \cdots \pi$ & 0.0071 & 0.0093 & 0.0266 \\
MeOH-Th (b) & $\mathrm{O}-\mathrm{H} \cdots \mathrm{S}$ & 0.0041 & 0.0094 & 0.0251
\end{tabular}

${ }^{a}$ All values are in a.u. bonded conformers are more strongly bound than the corresponding $\mathrm{O}-\mathrm{H} \cdots \pi$ hydrogen bonded conformers. Concerning for the $\mathrm{MeOH}-\mathrm{Py}$ complexes, the $\mathrm{BE}$ of the $\mathrm{N}-\mathrm{H} \cdots \mathrm{O}$ bonded $\mathrm{Py}-$ $\mathrm{MeOH}(\mathrm{b})$ is much less negative than that of $\mathrm{O}-\mathrm{H} \cdots \pi$ bonded $\mathrm{MeOH}-\mathrm{Py}$ (a) complex. For the three other $\mathrm{MeOH}$-complexes that are formed by furan, DHF and thiophene, the $\mathrm{O}-\mathrm{H} \cdots \pi$ bonded conformers (a) have less negative $\Delta H^{\theta}$ and larger $\Delta G^{\theta}$ than the corresponding conformers (b). The calculated BE and $\Delta H^{\theta}$ values of $\mathrm{O}-\mathrm{H} \cdots \pi$ and $\mathrm{O}-\mathrm{H} \cdots \mathrm{S}$ bonded conformers of the $\mathrm{MeOH}-\mathrm{Th}$ complex are very similar (differing by less than $1 \mathrm{~kJ}$ $\mathrm{mol}^{-1}$ ). However, the $\Delta G^{\theta}$ value of the $\mathrm{MeOH}-\mathrm{Th}$ (b) conformer is smaller than the corresponding value of the $\mathrm{MeOH}-\mathrm{Th}$ (a) conformer. Based on all the thermodynamic parameters presented above, the stability order of the two conformers of each $\mathrm{MeOH}$-complex is as follows, $\mathrm{MeOH}-\mathrm{Fu}$ (b) > MeOH-Fu (a), MeOH-DHF (b) > MeOH-DHF (a), Py-MeOH (b) > MeOH-Py (a) and $\mathrm{MeOH}-\mathrm{Th}(\mathrm{b}) \approx \mathrm{MeOH}-\mathrm{Th}(\mathrm{a})$. Consequently, the $\mathrm{MeOH}-$ Fu (b), MeOH-DHF (b), Py-MeOH (b) and both $\mathrm{O}-\mathrm{H} \cdots \pi$ and $\mathrm{O}-\mathrm{H} \cdots \mathrm{S}$ bonded $\mathrm{MeOH}-\mathrm{Th}$ complexes are more likely to be

Table 3 Calculated binding energies (BE), zero point vibrational energy (ZPVE), enthalpies of formation $\left(\Delta H^{\theta}\right)$, and Gibbs free energies of formation $\left(\Delta G^{\theta}\right)$ for the $\mathrm{MeOH}-\mathrm{Fu}, \mathrm{MeOH}-\mathrm{DHF}, \mathrm{MeOH}-\mathrm{Py}$ and $\mathrm{MeOH}-\mathrm{Th}$ complexes, calculated with the B3LYP functional

\begin{tabular}{llrlrl}
\hline Conformer $^{a}$ & Bond type & $\mathrm{BE}^{b}$ & ZPVE & \multicolumn{1}{c}{$\Delta H^{\theta}$} & $\Delta G^{\theta}$ \\
\hline MeOH-Fu (a) & $\mathrm{O}-\mathrm{H} \cdots \pi$ & -4.5 & 2.5 & -1.7 & 22.5 \\
MeOH-Fu (b) & $\mathrm{O}-\mathrm{H} \cdots \mathrm{O}$ & -7.1 & 3.3 & -4.7 & 20.6 \\
MeOH-DHF (a) & $\mathrm{O}-\mathrm{H} \cdots \pi$ & -3.7 & 2.7 & -0.9 & 22.1 \\
MeOH-DHF (b) & $\mathrm{O}-\mathrm{H} \cdots \mathrm{O}$ & -15.8 & 5.1 & -14.3 & 16.3 \\
MeOH-Py (a) & $\mathrm{O}-\mathrm{H} \cdots \pi$ & -8.1 & 3.1 & -5.6 & 21.1 \\
Py-MeOH (b) & $\mathrm{N}-\mathrm{H} \cdots \mathrm{O}$ & -16.4 & 3.6 & -13.9 & 13.4 \\
MeOH-Th (a) & $\mathrm{O}-\mathrm{H} \cdots \pi$ & -4.6 & 2.4 & -1.6 & 22.1 \\
MeOH-Th (b) & $\mathrm{O}-\mathrm{H} \cdots \mathrm{S}$ & -3.3 & 1.9 & 0.05 & 17.1
\end{tabular}

${ }^{a}$ The $\mathrm{MeOH}-\mathrm{Th}$ complexes are calculated with the aug-cc-pV(T+d)Z basis set, and all other complexes with the aug-cc-pVTZ basis set, respectively. ${ }^{b} \mathrm{BE}$ corrected with ZPVE. All energies are given in kJ $\mathrm{mol}^{-1} \cdot{ }^{c}$ In the Py-MeOH (b) complex, $\mathrm{MeOH}$ acts as hydrogen bond acceptor. 
formed in atmospheric environment. The nucleation trend shows a fundamental step in atmospheric new particle formation.

The BEs relevant for hydrogen bonding are also compared for the lowest energy conformers of every $\mathrm{MeOH}$ complexes. The maximum $\mathrm{BE}$ is predicted for the $\mathrm{Py}-\mathrm{MeOH}$ (b) conformer with a value of $-16.4 \mathrm{~kJ} \mathrm{~mol}^{-1}$. This is due to the presence of a strong $\mathrm{N}-\mathrm{H} \cdots \mathrm{O}$ hydrogen bond. The second most stable complex is $\mathrm{MeOH}-\mathrm{DHF}$ (b), which is $0.6 \mathrm{~kJ} \mathrm{~mol}^{-1}$ less stable than the Py$\mathrm{MeOH}$ (b) conformer. The following less stable structure is the $\mathrm{MeOH}-\mathrm{Fu}$ (b) conformer having a BEs of $7.1 \mathrm{~kJ} \mathrm{~mol}^{-1}$ with a weaker $\mathrm{O}-\mathrm{H} \cdots \mathrm{O}$ hydrogen bond. The $\mathrm{O}-\mathrm{H} \cdots \mathrm{O}$ bonded $\mathrm{MeOH}-$ Fu (b) has larger calculated $\mathrm{BE}, \Delta H^{\theta}$ and $\Delta G^{\theta}$ values than the $\mathrm{O}-\mathrm{H} \cdots \mathrm{S}$ bonded $\mathrm{MeOH}-\mathrm{Th}$ (b) conformer. These computed hydrogen bond indicators nicely correlate with the previous work, which showed that $\mathrm{O}-\mathrm{H} \cdots \mathrm{S}$ hydrogen bond is weaker than the $\mathrm{O}-\mathrm{H} \cdots \mathrm{O}$ hydrogen bond. ${ }^{54}$ Besides, this difference in hydrogen bond strength is reflected in the $\mathrm{OH}$-stretching vibrational frequencies calculated for the $\mathrm{MeOH}-\mathrm{Fu}$ and $\mathrm{MeOH}-\mathrm{Th}$ complexes.

\subsection{IR spectra}

The hydrogen bonds in the $\mathrm{MeOH}$ complexes were detected with matrix isolation FTIR. The argon matrix infrared spectra of $\mathrm{MeOH}$ complexes in the $\mathrm{OH}$-stretching fundamental transition $\tilde{\nu}_{\mathrm{OH}}$ region were measured after the matrix annealed to $14 \mathrm{~K}$. In the spectra of the $\mathrm{MeOH}$ complexes, bands with new features that were not present in the two monomers were marked with asterisk, which indicates the formation of the complexes. The spectra of $\mathrm{MeOH}$, furan, and the $\mathrm{MeOH}-\mathrm{Fu}$ complex are presented in Fig. 3. Different mixing ratios of $\mathrm{Fu} / \mathrm{MeOH}$ were applied to confirm the formation of the hydrogen-bonded complex. The two lower spectra in Fig. 3 are the monomers of furan (trace a) and $\mathrm{MeOH}$ (trace b). Trace $\mathrm{c}$ and $\mathrm{d}$ are spectra of the $\mathrm{MeOH}-\mathrm{Fu}$ complexes with different $\mathrm{Fu} / \mathrm{MeOH}$ mixing ratio,

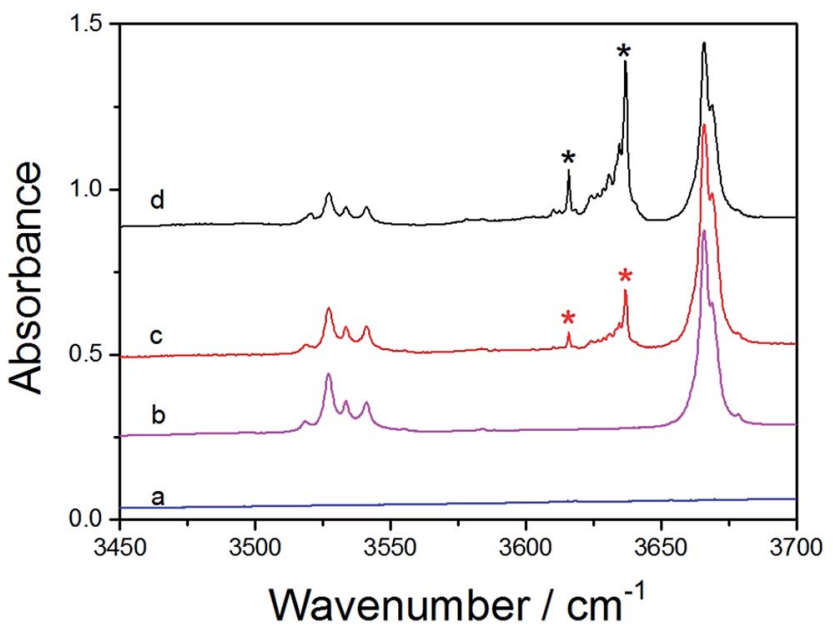

Fig. 3 Infrared spectra of $\mathrm{MeOH}$, furan, and the co-deposition of them at $14 \mathrm{~K}$. (a) $\mathrm{Fu} / \mathrm{Ar}=1 / 700$; (b) $\mathrm{MeOH} / \mathrm{Ar}=1 / 700$; (c) $\mathrm{MeOH} / \mathrm{Fu} / \mathrm{Ar}=1 / 1$ / 700; (d) $\mathrm{MeOH} / \mathrm{Fu} / \mathrm{Ar}=1 / 5 / 700$. Bands marked with asterisk are new features from $\mathrm{MeOH}-\mathrm{Fu}$ complex. The spectra were offset for clarity.
1:1 for trace $\mathrm{c}$ and $5: 1$ for trace $\mathrm{d}$. The fundamental $\mathrm{OH}^{-}$ stretching frequency in $\mathrm{MeOH}$ is found to be $\sim 3666 \mathrm{~cm}^{-1}$. In the spectra of $\mathrm{MeOH}-\mathrm{Fu}$ complexes, this band has also been detected. Features due to the red shifts $\left(\Delta \tilde{\nu}_{\mathrm{OH}}\right)$ of the $\mathrm{OH}$ stretching fundamental transition of $\mathrm{MeOH}$ were observed at $\sim 3616 \mathrm{~cm}^{-1}$ and $\sim 3635 \mathrm{~cm}^{-1}$ in the spectrum of the $\mathrm{MeOH}-\mathrm{Fu}$ complex, it is assigned here to the $\mathrm{OH}$-stretching transition frequency of the $1: 1 \mathrm{MeOH}-\mathrm{Fu}$ (b) complex due to its stronger $\mathrm{O}-\mathrm{H} \cdots \mathrm{O}$ hydrogen bond. The intensity of the $\mathrm{OH}$-stretching frequency of the $\mathrm{MeOH}$ monomer decreases with increasing $\mathrm{Fu} / \mathrm{MeOH}$ mixing ratio because part of $\mathrm{MeOH}$ takes part in the formation of $\mathrm{MeOH}-\mathrm{Fu}$ complex forming the $\mathrm{O}-\mathrm{H} \cdots \mathrm{O}$ hydrogen bond. Furthermore, since increasing the proportion of the furan leads to more $\mathrm{MeOH}$-complex formation, the intensity of the $\mathrm{OH}$-stretching frequency of the $\mathrm{MeOH}-\mathrm{Fu}$ complex increases with the increment of adding proportion on furan. It should be mentioned that the $3530 \mathrm{~cm}^{-1}$ band which decreases slightly with increasing $\mathrm{Fu} / \mathrm{MeOH}$ mixing ratio is recorded in all infrared spectra of the $\mathrm{MeOH}$ monomer and the corresponding $\mathrm{MeOH}$ complexes investigated in this study. We assign these features to the dimer of $\mathrm{MeOH}$. Similar phenomenon has been found in previous studies. ${ }^{27,55}$ With the formation of $\mathrm{MeOH}$ complexes, $\mathrm{MeOH}$ tends to interact stronger with heterocyclic organic compounds forming hydrogen bonded complexes rather than forming $\mathrm{MeOH}$ dimer.

The FTIR spectra of $\mathrm{MeOH}, \mathrm{DHF}$, and $\mathrm{MeOH}-\mathrm{DHF}$ are shown in Fig. 4. In the infrared absorption spectra, the 3488 and 3563 $\mathrm{cm}^{-1}$ bands are the $\mathrm{OH}$-stretching fundamental transition of the $\mathrm{MeOH}-\mathrm{DHF}$ complex with calculated $\mathrm{OH}$-stretching mode frequency $3643 \mathrm{~cm}^{-1}$ and $3768 \mathrm{~cm}^{-1}$ (Table 4). This assignment is underscored by the distinct intensity evolution of these bands when varying the relative DHF concentration. Stronger $\mathrm{OH}-$ stretching vibration bands of the $\mathrm{MeOH}-\mathrm{DHF}$ complex are observed in higher $\mathrm{DHF} / \mathrm{MeOH}$ mixing ratio. The complex spectra obtained from the matrix isolation experiment belong

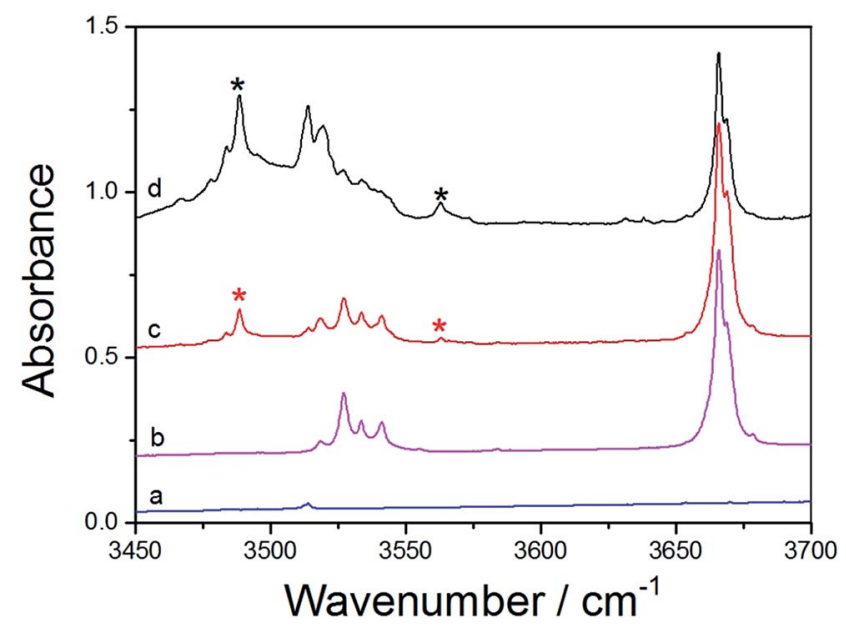

Fig. 4 Infrared spectra of $\mathrm{MeOH}, \mathrm{DHF}$, and the co-deposition of them at $14 \mathrm{~K}$. (a) $\mathrm{DHF} / \mathrm{Ar}=1 / 700$; (b) $\mathrm{MeOH} / \mathrm{Ar}=1 / 700$; (c) $\mathrm{MeOH} / \mathrm{DHF} / \mathrm{Ar}=$ 1/1/700; (d) $\mathrm{MeOH} / \mathrm{DHF} / \mathrm{Ar}=1 / 5 / 700$. Bands marked with asterisk are new features from $\mathrm{MeOH}-\mathrm{DHF}$ complex. The spectra were offset for clarity. 
Table 4 Calculated and observed $\mathrm{OH}$-stretching fundamental transition wavenumbers and red shifts $\left(\mathrm{cm}^{-1}\right)$

\begin{tabular}{|c|c|c|c|c|c|c|}
\hline Conformer & \multicolumn{4}{|c|}{ Calculated } & \multicolumn{2}{|l|}{ Observed } \\
\hline $\mathrm{MeOH}-\mathrm{Fu}(\mathrm{a})$ & 3770 & 58 & $4.2 \times 10^{-5}$ & 7.3 & 3635,3616 & $31-50$ \\
\hline $\mathrm{MeOH}-\mathrm{Fu}(\mathrm{b})$ & 3772 & 56 & $6.2 \times 10^{-5}$ & 10.6 & & \\
\hline $\mathrm{MeOH}-\mathrm{DHF}$ (a) & 3766 & 61 & $4.4 \times 10^{-5}$ & 7.5 & 3488,3563 & $103-178$ \\
\hline Py-MeOH (b) ${ }^{b}$ & 3537 & 134 & $1.1 \times 10^{-4}$ & 18.8 & 3371 & 149 \\
\hline $\mathrm{MeOH}-\mathrm{Th}(\mathrm{a})$ & 3775 & 53 & $4.1 \times 10^{-5}$ & 7.0 & 3636,3614 & $30-60$ \\
\hline $\mathrm{MeOH}-\mathrm{Th}(\mathrm{b})$ & 3775 & 53 & $4.0 \times 10^{-5}$ & 6.9 & & \\
\hline
\end{tabular}

${ }^{a} \Delta \tilde{\nu}_{\mathrm{OH}}=\tilde{\nu}_{\mathrm{MeOH}}-\tilde{\nu}_{\text {complex }}{ }^{b}$ In the Py-MeOH (b) complex, MeOH acts as hydrogen bond acceptor. $\Delta \tilde{\nu}_{\mathrm{NH}}=\tilde{\nu}_{\text {pyrrole }}-\tilde{\nu}_{\text {complex }}$. The calculated NHstretching transition wavenumber of pyrrole is $3671 \mathrm{~cm}^{-1}$. ${ }^{c}$ The observed NH-stretching transition wavenumber of pyrrole is $3520 \mathrm{~cm}^{-1}$.

to the more stable $\mathrm{O}-\mathrm{H} \cdots \mathrm{O}$ hydrogen-bonded $\mathrm{MeOH}-\mathrm{DHF}(\mathrm{b})$ complex according to the geometric and thermodynamic parameters discussed above. Similar measurements for the $\mathrm{MeOH}-\mathrm{Th}$ and $\mathrm{MeOH}-\mathrm{Py}$ complex were also carried out and the results are shown in Fig. 5 and S2, $\uparrow$ respectively. The feature observed at $3666 \mathrm{~cm}^{-1}$ is due to $\mathrm{MeOH}$ monomer. The features observed around $3530 \mathrm{~cm}^{-1}$ are due to $\mathrm{MeOH}$ dimer, which agrees well with the literature value. ${ }^{55}$ The fundamental $\mathrm{OH}^{-}$ stretching frequencies of $\mathrm{MeOH}-\mathrm{Th}$ complex are recorded at $3614 \mathrm{~cm}^{-1}, 3636 \mathrm{~cm}^{-1}$ in the infrared absorption spectra (calculated value $3776 \mathrm{~cm}^{-1}$ (Table 4)). It is hard to assign the spectra to the exact $\mathrm{MeOH}-\mathrm{Th}$ conformer, because all hydrogen bond characteristic features we obtained for different $\mathrm{MeOH}-$ Th conformers are too close. It is likely that the two MeOH-Th conformers co-exist in the atmosphere. The integration regions for $\mathrm{MeOH}-\mathrm{Py}$ are $3300-3700 \mathrm{~cm}^{-1}$. As shown in Fig. S2, $\dagger$ $\mathrm{MeOH}-\mathrm{Py}$ (a) and $\mathrm{Py}-\mathrm{MeOH}$ (b) were all detected in our matrix isolation experiments. The $3581 \mathrm{~cm}^{-1}, 3583 \mathrm{~cm}^{-1}$ bands which

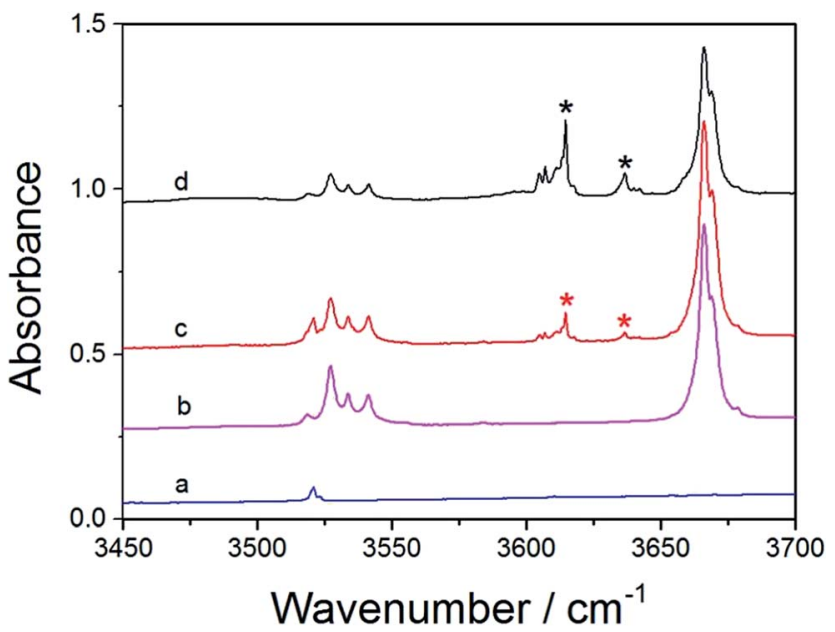

Fig. 5 Infrared spectra of $\mathrm{MeOH}$, thiophene, and the co-deposition of them at $14 \mathrm{~K}$. (a) $\mathrm{Th} / \mathrm{Ar}=1 / 700$; (b) $\mathrm{MeOH} / \mathrm{Ar}=1 / 700$; (c) $\mathrm{MeOH} / \mathrm{Th} / \mathrm{Ar}$ $=1 / 1 / 700 ;$ (d) $\mathrm{MeOH} / \mathrm{Th} / \mathrm{Ar}=1 / 5 / 700$. Bands marked with asterisk are new features from $\mathrm{MeOH}-\mathrm{Th}$ complex. The spectra were offset for clarity. have a small red shifts $\left(\Delta \tilde{\nu}_{\mathrm{OH}}\right)$ are assigned to the $\mathrm{MeOH}-\mathrm{Py}(\mathrm{a})$. It is plausible to assign the $3371 \mathrm{~cm}^{-1}$ band to the $\mathrm{Py}-\mathrm{MeOH}(\mathrm{b})$, which is significantly lower in energy than the $\mathrm{MeOH}-\mathrm{Py}$ (a) complex and has a larger red shifts $\left(\Delta \tilde{\nu}_{\mathrm{OH}}\right)$. The calculated fundamental $\mathrm{OH}$-stretching frequencies for the $\mathrm{MeOH}-\mathrm{Py}$ complexes are $3740 \mathrm{~cm}^{-1}$, and $3536 \mathrm{~cm}^{-1}$. And this assignment follows the expected trend with the calculated results of the red shifts $\left(\Delta \tilde{\nu}_{\mathrm{OH}}\right)$ in $\mathrm{MeOH}-\mathrm{Py}$ complexes (Table 4$)$.

The OH-stretching bands of $\mathrm{MeOH}-\mathrm{Fu}$ and $\mathrm{MeOH}-\mathrm{Th}$ complexes show similar profile (Fig. S1 $\dagger$ ), which demonstrates that formation of hydrogen bond in the $\mathrm{MeOH}-\mathrm{Fu}$ complex is similar to the one in the $\mathrm{MeOH}-\mathrm{Th}$ complex. The $\mathrm{OH}$-stretching transition frequency of $\mathrm{MeOH}-\mathrm{Fu}\left(3616,3635 \mathrm{~cm}^{-1}\right)$ is similar to the one in the MeOH-Th complex $\left(3614,3636 \mathrm{~cm}^{-1}\right)$. This confirms that these two MeOH-complexes are formed in a similar way, and $\mathrm{S}$ is an acceptor atom similar in strength to $\mathrm{O}$. The previous experimental studies on methionine-tyrosine hydrogen bonded complexes also indicate that $\mathrm{O}-\mathrm{H} \cdots \mathrm{S}$ interaction is perhaps as strong as $\mathrm{O}-\mathrm{H} \cdots \mathrm{O}$ interaction..$^{56}$ However, the $\mathrm{OH}$-stretching transition frequency of $\mathrm{MeOH}-\mathrm{Py}(3581,3583$ $\mathrm{cm}^{-1}$ ) is smaller than those of $\mathrm{MeOH}-\mathrm{Fu}$ and $\mathrm{MeOH}-\mathrm{Th}$ complexes. Comparing the fundamental $\mathrm{OH}$-stretching transition frequencies of the two different $\mathrm{MeOH}-\mathrm{Py}$ complexes, we found that our measured $\mathrm{OH}$-stretching frequency of $\mathrm{MeOH}-\mathrm{Py}$ (a) $\left(3581,3583 \mathrm{~cm}^{-1}\right)$ is much larger than that of $\mathrm{Py}-\mathrm{MeOH}(\mathrm{b})$ (3371 $\mathrm{cm}^{-1}$ ), and therefore, the $\mathrm{Py}-\mathrm{MeOH}$ (b) complex is significantly more stable than the $\mathrm{MeOH}-\mathrm{Py}$ (a) complex. Similar findings were also observed from quantum chemical calculations performed in this study. In addition, the $\mathrm{OH}^{-}$ stretching transition frequency of $\mathrm{MeOH}-\mathrm{DHF}$ (3488, 3563 $\left.\mathrm{cm}^{-1}\right)$ is smaller than that of MeOH-Fu complex $(3653,3616$ $\mathrm{cm}^{-1}$ ). Accordingly, DHF forms stronger $\mathrm{O}-\mathrm{H} \cdots \mathrm{O}$ hydrogen bonded complexes than furan.

The red shift value $\left(\Delta \tilde{\nu}_{\mathrm{OH}}\right)$ of the $\mathrm{OH}$-stretching transitions $\left(\Delta \tilde{\nu}_{\mathrm{OH}}=\tilde{\nu}_{\mathrm{MeOH}}-\tilde{\nu}_{\text {complex }}\right)$ correlates with the hydrogen bond strength. The smaller shift in the complex points out a weaker hydrogen bond formation. The observed bands origin for the complexes are red shifted with respect to their respective monomers. The observed and calculated fundamental $\mathrm{OH}^{-}$ stretching transition frequency and the red shifts $\left(\Delta \tilde{\nu}_{\mathrm{OH}}\right)$ of 
the fundamental $\mathrm{OH}$-stretching in the complexes are summarized in Table 4 . The maximum red shifts $\left(\Delta \tilde{\nu}_{\mathrm{OH}}\right)$ are observed for $\mathrm{O}-\mathrm{H} \cdots \mathrm{O}$ hydrogen bonded $\mathrm{MeOH}-\mathrm{DHF}$ complex $(103,178$ $\mathrm{cm}^{-1}$ ) followed by $\mathrm{N}-\mathrm{H} \cdots \mathrm{O}$ hydrogen bonded $\mathrm{Py}-\mathrm{MeOH}$ (b) $(149$ $\left.\mathrm{cm}^{-1}\right), \mathrm{O}-\mathrm{H} \cdots \pi$ hydrogen bonded $\mathrm{MeOH}-\mathrm{Py}$ (a) $\left(85,87 \mathrm{~cm}^{-1}\right)$, $\mathrm{O}-\mathrm{H} \cdots \mathrm{O}$ hydrogen bonded $\mathrm{MeOH}-\mathrm{Fu}$ complex $\left(31,50 \mathrm{~cm}^{-1}\right.$ ) and $\mathrm{O}-\mathrm{H} \cdots \mathrm{S}$ hydrogen bonded $\mathrm{MeOH}-\mathrm{Th}$ complex $(30,60$ $\left.\mathrm{cm}^{-1}\right)$. The magnitudes of the red shifts $\left(\Delta \tilde{\nu}_{\mathrm{OH}}\right)$ observed in $\mathrm{MeOH}-\mathrm{Fu}$ complex are similar to those observed in $\mathrm{MeOH}-\mathrm{Th}$ complexes, but they are all smaller than those of MeOH-DHF and $\mathrm{MeOH}-\mathrm{Py}$ (a). Of all the $\mathrm{MeOH}$ complexes studied here, Py$\mathrm{MeOH}(\mathrm{b})$ has larger red shifts $\left(\Delta \tilde{\nu}_{\mathrm{OH}}\right)$ of the NH-stretching fundamental transition than $\mathrm{MeOH}-\mathrm{Py}$ (a), which would suggest that $\mathrm{N}-\mathrm{H} \cdots \mathrm{O}$ hydrogen bonded $\mathrm{Py}-\mathrm{MeOH}(\mathrm{b})$ is more stable than $\mathrm{O}-\mathrm{H} \cdots \pi$ hydrogen bonded $\mathrm{MeOH}-\mathrm{Py}(\mathrm{a})$. Hence, the hydrogen bond strength for $\mathrm{MeOH}$-complexes can be sorted as follows: DHF forms stronger $\mathrm{O}-\mathrm{H} \cdots \mathrm{Y}(\mathrm{Y}=\mathrm{O}, \mathrm{S})$ hydrogen bond than furan and thiophene, which is attributed to the nonaromatic properties of DHF. In addition, the $\mathrm{O}-\mathrm{H} \cdots \mathrm{S}$ hydrogen bond strength of $\mathrm{MeOH}-\mathrm{Th}$ is almost similar to $\mathrm{O}-\mathrm{H} \cdots \mathrm{O}$ of the $\mathrm{MeOH}-\mathrm{Fu}$ complex. These observed trends are in excellent agreement with the former measurement for other analogous hydrogen bonded complexes, which depicted that MeOH-TMA $\left(\Delta \tilde{\nu}_{\mathrm{OH}}=333 \mathrm{~cm}^{-1}\right)$ is more stable than MeOH-DMS $\left(\Delta \tilde{\nu}_{\mathrm{OH}}=113\right.$ $\left.\mathrm{cm}^{-1}\right)$ and $\mathrm{MeOH}-\mathrm{DME}\left(\Delta \tilde{\nu}_{\mathrm{OH}}=103 \mathrm{~cm}^{-1}\right) \cdot{ }^{24,55,57}$ Experimental studies of $\mathrm{MeOH}$-complex under different temperature conditions have drawn the same conclusion as well. The spectra of the mixture recorded at $14 \mathrm{~K}$ and $25 \mathrm{~K}$ are shown in Fig. S1. $\dagger$ The intensity of the $\mathrm{OH}$-stretching frequency of the $\mathrm{MeOH}$ monomer decreases slightly with increasing temperature. Similar trend is also found in the bands of $\mathrm{MeOH}$ dimer. In contrast, the features of the relevant bands of the $\mathrm{MeOH}$-complex formation are more obvious when the annealing temperature increases from $14 \mathrm{~K}$ to $25 \mathrm{~K}$. This phenomenon also provides evidence to the formation of four different $\mathrm{MeOH}$-complexes. Furthermore, we can also conclude that increasing temperature favors the complexes formation. A recent study about the thermodynamic properties of gas phase hydrogen bonded complexes has also confirmed that the $\mathrm{OH}$-stretching vibration in the $\mathrm{MeOH}-\mathrm{DMA}$ complex is temperature dependent. ${ }^{58}$ More detailed information of the co-deposition of $\mathrm{MeOH}$ and pyrrole are shown in Fig. S2. $\dagger$ The trend observed in the intermolecular stretching frequencies and relative red shifts of $\mathrm{OH}$-stretching in the FTIR spectra are consistent with the binding energy values calculated with DFT methods.

\subsection{Calculated $\mathrm{OH}$-stretching transitions and intensities}

Vibrational frequency calculations were performed on the optimized geometries to help assigning the wavenumbers observed in the matrix isolation experiment. The calculated $\mathrm{OH}-$ stretching frequencies are listed in Table 4. The experimental and calculated red shifts $\left(\Delta \tilde{\nu}_{\mathrm{OH}}\right)$ of $\mathrm{OH}$-stretching fundamental transition are also included. The experimental observations of $\mathrm{OH}$-stretching fundamental vibrations wavenumbers are smaller than the calculated frequencies with respect to the monomer. The calculated red shifts of $\mathrm{MeOH}$-complexes follow the same trends as the experimental observations. As given in Table 4 , the calculated red shift $\left(\Delta \tilde{\nu}_{\mathrm{OH}}\right)$ with the $\pi$-type hydrogen bond is in the range $53-90 \mathrm{~cm}^{-1}$, which is larger than that in previous studies which described that $\mathrm{OH}$-stretching red shifts is about $45 \mathrm{~cm}^{-1}$ for weak intermolecular $\mathrm{O}-\mathrm{H} \cdots \pi$ hydrogen bond in $\mathrm{MeOH}-$ ethene complex. ${ }^{7}$ The maximum calculated red shifts $\left(\Delta \tilde{\nu}_{\mathrm{OH}}\right)$ is the $\mathrm{O}-\mathrm{H} \cdots \mathrm{O}$ hydrogen bonded $\mathrm{MeOH}-\mathrm{DHF}$ complex $\left(190 \mathrm{~cm}^{-1}\right)$ followed by $\mathrm{Py}-\mathrm{MeOH}$ (b) $\left(134 \mathrm{~cm}^{-1}\right)$, MeOH-Py (a) $\left(90 \mathrm{~cm}^{-1}\right), \mathrm{O}-\mathrm{H} \cdots \pi$ hydrogen bonded MeOH-DHF (a) $\left(61 \mathrm{~cm}^{-1}\right), \mathrm{MeOH}-\mathrm{Fu}$ (a) $\left(58 \mathrm{~cm}^{-1}\right), \mathrm{MeOH}-\mathrm{Fu}$ (b) $\left(56 \mathrm{~cm}^{-1}\right)$ and $\mathrm{MeOH}-\mathrm{Th}$ complex $\left(53 \mathrm{~cm}^{-1}\right)$. The results agree well with the experimental red shifts, and thus indicate that the hydrogen bond strength of $\mathrm{O}-\mathrm{H} \cdots \mathrm{O}$ in $\mathrm{MeOH}-\mathrm{Fu}$ complexes is similar to $\mathrm{O}-\mathrm{H} \cdots \mathrm{S}$ hydrogen bond in the $\mathrm{MeOH}-\mathrm{Th}$ complexes. In $\mathrm{O}-\mathrm{H} \cdots \mathrm{O}$ hydrogen bonded complexes, $\mathrm{MeOH}-\mathrm{DHF}$ is more stable than $\mathrm{MeOH}-\mathrm{Fu}$ complex because oxygen atom in furan is affected by the delocalization of $\pi$-electrons in the furan ring, thus forming the weaker $\mathrm{O}-\mathrm{H} \cdots \mathrm{O}$ hydrogen bond.

The oscillator strength $(f)$ and the relative intensities $(f)$ $f_{\mathrm{MeOH}}$ ) of the $\mathrm{OH}$-stretching fundamental transition for the complexes are also listed in Table 4. The oscillator strengths of $\mathrm{OH}$-stretching vibrations in $\mathrm{MeOH}$ complexes were over seven times stronger than $\mathrm{MeOH}$ monomer as a result of hydrogen bond formation. In addition, we found that the calculated oscillator strengths of the two different conformers of a same complex are quite different except for the $\mathrm{MeOH}-\mathrm{Th}$ complex. The oscillator strengths of $\mathrm{O}-\mathrm{H} \cdots \pi$ hydrogen bonded conformers are smaller than $\mathrm{O}-\mathrm{H} \cdots \mathrm{O}$ hydrogen bonded conformers, which means that the conformer (b) of the $\mathrm{MeOH}-$ $\mathrm{Fu}$ and $\mathrm{MeOH}-\mathrm{Th}$ complexes is more stable than the conformer (a). This trend is also suitable for $\mathrm{MeOH}-\mathrm{Py}$ complexes, as the strength of $\mathrm{Py}-\mathrm{MeOH}$ (b) conformer is almost twice that of $\mathrm{MeOH}-\mathrm{Py}$ (a) conformer. Nevertheless, there is no significant difference in oscillator strength between the $\mathrm{O}-\mathrm{H} \cdots \pi(4.1 \times$ $\left.10^{-5}\right)$ and $\mathrm{O}-\mathrm{H} \cdots \mathrm{S}\left(4.0 \times 10^{-5}\right)$ bonded conformers of the $\mathrm{MeOH}-\mathrm{Th}$ complex. As the values are too close to each other, it is hard to tell which bond is stronger based on the relative intensities.

\section{Conclusions}

A competition between $\mathrm{O}-\mathrm{H} \cdots \mathrm{O} / \mathrm{S}$ and $\mathrm{O}-\mathrm{H} \cdots \pi$ binding sites exists in $\mathrm{MeOH}$ complexes when $\mathrm{MeOH}$ dock onto the heterocyclic organic compounds, such as furan, DHF, pyrrole and thiophene. To compare the competition between these two different bonding sites, we have investigated the hydrogen bond $\mathrm{MeOH}$ complexes using matrix isolation FTIR spectroscopy and theoretical calculations. Obviously, two different configurations (X-H $\cdots \mathrm{Y}$ and $\mathrm{O}-\mathrm{H} \cdots \pi$ hydrogen bonded conformers) in each $\mathrm{MeOH}$-complex were obtained. Generally, the structures with a hydrogen bond to the heteroatom are more stable than those bonding to the $\pi$ systems. AIM results clearly predict the nature of interaction in $\mathrm{MeOH}$ complexes, and indicate the presence of the hydrogen bond between $\mathrm{MeOH}$ and the heterocyclic organic compounds. The measured $\mathrm{OH}$-stretching transitions of the complexes were assigned as from the $\mathrm{O}-\mathrm{H} \cdots \mathrm{Y}(\mathrm{Y}=\mathrm{O}, \mathrm{S})$ bonded structures, and the $\mathrm{N}-\mathrm{H} \cdots \mathrm{O}$ bonded $\mathrm{Py}-\mathrm{MeOH}$ complexes. The 
observed red shifts $\left(\Delta \tilde{\nu}_{\mathrm{OH}}\right)$ of the $\mathrm{OH}$-stretching fundamental transition are consistent with the theoretical computational results, which confirms that the complex spectra of $\mathrm{MeOH}-\mathrm{Fu}$ and $\mathrm{MeOH}-\mathrm{DHF}$ complexes obtained from the matrix isolation experiment belong to the $\mathrm{O}-\mathrm{H} \cdots \mathrm{O}$ hydrogen bonded complexes. However, the $\mathrm{O}-\mathrm{H} \cdots \pi$ bonded $\mathrm{MeOH}-\mathrm{Th}$ (a) conformer may coexist with the $\mathrm{O}-\mathrm{H} \cdots \mathrm{S}$ bonded $\mathrm{MeOH}-\mathrm{Th}$ (b) conformer since all the values obtained from theoretical calculations for different $\mathrm{MeOH}-\mathrm{Th}$ conformers are very close to each other. In addition, comparison of the red shifts $\left(\Delta \tilde{\nu}_{\mathrm{OH}}\right)$ of the OH-stretching fundamental transition of the complexes shows that $\mathrm{MeOH}-$ DHF is more stable than $\mathrm{MeOH}-\mathrm{Fu}$ complex, while the hydrogen bond strength of $\mathrm{O}-\mathrm{H} \cdots \mathrm{O}$ in $\mathrm{MeOH}-\mathrm{Fu}$ complexes is similar to $\mathrm{O}-\mathrm{H} \cdots \mathrm{S}$ hydrogen bond in the $\mathrm{MeOH}-\mathrm{Th}$ complexes. The results of this study help to understand the nature of hydrogen bonds in $\mathrm{MeOH}$-complexes and their implication in new particle formation.

\section{Acknowledgements}

This work was supported by National Natural Science Foundation of China (21577080, 91644214, 21407095) and Shandong Provincial Natural Science Foundation, China (ZR2014BQ013).

\section{Notes and references}

1 F. Bianchi, J. Trostl, H. Junninen, C. Frege, S. Henne, C. R. Hoyle, U. Molteni, E. Herrmann, A. Adamov, N. Bukowiecki, X. Chen, J. Duplissy, M. Gysel, M. Hutterli, J. Kangasluoma, J. Kontkanen, A. Kuerten, H. E. Manninen, S. Muench, O. Perakyla, T. Petaja, L. Rondo, C. Williamson, E. Weingartner, J. Curtius, D. R. Worsnop, M. Kulmala, J. Dommen and U. Baltensperger, Science, 2016, 352, 1109-1112.

2 R. Zhang, Science, 2010, 328, 1366-1367.

3 J. Zhao, A. Khalizov, R. Zhang and R. McGraw, J. Phys. Chem. A, 2009, 113, 680-689.

4 P. Paasonen, T. Olenius, O. Kupiainen, T. Kurten, T. Petaja, W. Birmili, A. Hamed, M. Hu, L. G. Huey, C. PlassDuelmer, J. N. Smith, A. Wiedensohler, V. Loukonen, M. J. McGrath, I. K. Ortega, A. Laaksonen, H. Vehkamaki, V. M. Kerminen and M. Kulmala, Atmos. Chem. Phys., 2012, 12, 9113-9133.

5 M. Voehringer, E. B. Hansmann, H. Hernandez, J. S. Francisco, J. Troe and B. Abel, Science, 2007, 315, 497501.

6 B. Long, X. F. Tan, C. R. Chang, W. X. Zhao, Z. W. Long, D. S. Ren and W. J. Zhang, J. Phys. Chem. A, 2013, 117, 5106-5116.

7 M. Heger, R. A. Mata and M. A. Suhm, Chem. Sci., 2015, 6, 3738-3745.

8 S. Tang, H. Zhao and L. Du, RSC Adv., 2016, 6, 91233-91242. 9 B. J. van der Veken, W. A. Herrebout, R. Szostak, D. N. Shchepkin, Z. Havlas and P. Hobza, J. Am. Chem. Soc., 2001, 123, 12290-12293.

10 M. Rozenberg, A. Loewenschuss and C. J. Nielsen, J. Phys. Chem. A, 2015, 119, 8497-8502.
11 A. A. Stolov, W. A. Herrebout and B. J. van der Veken, J. Am. Chem. Soc., 1998, 120, 7310-7319.

12 F. Kollipost, J. Andersen, D. W. Mahler, J. Heimdal, M. Heger, M. A. Suhm and R. W. Larsen, J. Chem. Phys., 2014, 141, 174314.

13 K. E. Otto, S. Hesse, T. N. Wassermann, C. A. Rice, M. A. Suhm, T. Stafforst and U. Diederichsen, Phys. Chem. Chem. Phys., 2011, 13, 14119-14130.

14 A. Sharma, I. Reva, R. Fausto, S. Hesse, Z. Xue, M. A. Suhm, S. K. Nayak, R. Sathishkumar, R. Pal and T. N. G. Row, J. Am. Chem. Soc., 2011, 133, 20194-20207.

15 M. Rozenberg, A. Loewenschuss and C. J. Nielsen, J. Phys. Chem. A, 2012, 116, 4089-4096.

16 M. Rozenberg and A. Loewenschuss, J. Phys. Chem. A, 2009, 113, 4963-4971.

17 M. Rozenberg, A. Loewenschuss and C. J. Nielsen, J. Phys. Chem. A, 2014, 118, 1004-1011.

18 M. Rozenberg, A. Loewenschuss and C. J. Nielsen, J. Phys. Chem. A, 2015, 119, 2271-2280.

19 J. P. Perchard, F. Romain and Y. Bouteiller, Chem. Phys., 2008, 343, 35-46.

20 M. Muzomwe, B. Boeckx, G. Maes and O. E. Kasende, S. Afr. J. Chem., 2011, 64, 23-33.

21 P. R. Joshi, N. Ramanathan, K. Sundararajan and K. Sankaran, J. Phys. Chem. A, 2015, 119, 3440-3451.

22 A. Mellouki, T. J. Wallington and J. Chen, Chem. Rev., 2015, 115, 3984-4014.

23 G. Legreid, J. B. Loeoev, J. Staehelin, C. Hueglin, M. Hill, B. Buchmann, A. S. H. Prevot and S. Reimann, Atmos. Environ., 2007, 41, 8409-8423.

24 L. Du, K. Mackeprang and H. G. Kjaergaard, Phys. Chem. Chem. Phys., 2013, 15, 10194-10206.

25 H. C. Gottschalk, J. Altnoeder, M. Heger and M. A. Suhm, Angew. Chem., Int. Ed., 2016, 55, 1921-1924.

26 D. L. Howard and H. G. Kjaergaard, J. Phys. Chem. A, 2006, 110, 9597-9601.

27 F. Kollipost, K. Papendorf, Y. F. Lee, Y. P. Lee and M. A. Suhm, Phys. Chem. Chem. Phys., 2014, 16, 15948-15956.

28 T. G. Karl, T. J. Christian, R. J. Yokelson, P. Artaxo, W. M. Hao and A. Guenther, Atmos. Chem. Phys., 2007, 7, 5883-5897.

29 T. B. Nguyen, A. Laskin, J. Laskin and S. A. Nizkorodov, Faraday Discuss., 2013, 165, 473-494.

30 S. Kumar, V. Pande and A. Das, J. Phys. Chem. A, 2012, 116, 1368-1374.

31 P. M. Lemieux, C. C. Lutes and D. A. Santoianni, Prog. Energy Combust. Sci., 2004, 30, 1-32.

32 F. Villanueva, B. Cabanas, E. Monedero, S. Salgado, I. Bejan and P. Martin, Atmos. Environ., 2009, 43, 2804-2813.

33 I. Kind, T. Berndt, O. Boge and W. Rolle, Chem. Phys. Lett., 1996, 256, 679-683.

34 T. J. Christian, B. Kleiss, R. J. Yokelson, R. Holzinger, P. J. Crutzen, W. M. Hao, B. H. Saharjo and D. E. Ward, J. Geophys. Res., 2003, 108, 1-13.

35 T. J. Christian, B. Kleiss, R. J. Yokelson, R. Holzinger, P. J. Crutzen, W. M. Hao, T. Shirai and D. R. Blake, J. Geophys. Res., 2004, 109, 1-12. 
36 B. Cabanas, M. T. Baeza, P. Martin, S. Salgado, F. Villanueva, E. Monedero and Y. D. De Mera, Int. J. Chem. Kinet., 2006, 38, 570-576.

37 H. Zhao, J. Chang and L. Du, Comput. Theor. Chem., 2016, 1084, 126-132.

38 H. Zhao, S. Tang, S. Li, L. Ding and L. Du, Struct. Chem., 2016, 27, 1241-1253.

39 L. Du, J. R. Lane and H. G. Kjaergaard, J. Chem. Phys., 2012, 136, 184305.

40 A. Becke, J. Chem. Phys., 1993, 98, 5648-5652.

41 A. Dkhissi, L. Adamowicz and G. Maes, J. Phys. Chem. A, 2000, 104, 2112-2119.

42 T. H. Dunning, K. A. Peterson and A. K. Wilson, J. Chem. Phys., 2001, 114, 9244-9253.

43 R. A. Kendall, T. H. Dunning Jr and R. J. Harrison, J. Chem. Phys., 1992, 96, 6796-6806.

44 V. Vaida and J. E. Headrick, J. Phys. Chem. A, 2000, 104, 54015412.

45 F. Tran and T. A. Wesolowski, Int. J. Quantum Chem., 2005, 101, 854-859.

46 R. G. A. Bone and R. F. W. Bader, J. Phys. Chem., 1996, 100, 10892-10911.

47 P. L. A. Popelier and R. F. W. Bader, Chem. Phys. Lett., 1992, 189, 542-548.
48 H. Sasaki, S. Daicho, Y. Yamada and Y. Nibu, J. Phys. Chem. A, 2013, 117, 3183-3189.

49 M. Heger, J. Altnoeder, A. Poblotzki and M. A. Suhm, Phys. Chem. Chem. Phys., 2015, 17, 13045-13052.

50 H. Sasaki, S. Daicho, Y. Yamada and Y. Nibu, J. Phys. Chem. A, 2013, 117, 3183-3189.

51 D. L. Howard and H. G. Kjaergaard, Phys. Chem. Chem. Phys., 2008, 10, 4113-4118.

52 E. Arunan, G. R. Desiraju, R. A. Klein, J. Sadlej, S. Scheiner, I. Alkorta, D. C. Clary, R. H. Crabtree, J. J. Dannenberg, P. Hobza, H. G. Kjaergaard, A. C. Legon, B. Mennucci and D. J. Nesbitt, Pure Appl. Chem., 2011, 83, 1619-1636.

53 R. F. W. Bader, Chem. Rev., 1991, 91, 893-928.

54 H. S. Biswal, P. R. Shirhatti and S. Wategaonkar, J. Phys. Chem. A, 2009, 113, 5633-5643.

55 A. S. Hansen, L. Du and H. G. Kjaergaard, J. Phys. Chem. Lett., 2014, 5, 4225-4231.

56 H. S. Biswal, S. Chakraborty and S. Wategaonkar, J. Chem. Phys., 2008, 129, 184311.

57 B. Michielsen, C. Verlackt, B. J. van der Veken and W. A. Herrebout, J. Mol. Struct., 2012, 1023, 90-95.

58 A. S. Hansen, Z. Maroun, K. Mackeprang, B. N. Frandsen and H. G. Kjaergaard, Phys. Chem. Chem. Phys., 2016, 18, 2383123839. 